\title{
The Innovative Nature Of Scientific Research In The Knowledge Management Process At Medical College
}

\author{
Juris Firsts, Riga Medical College No. 1, Latvia
}

\begin{abstract}
This paper examines the process specifics that affects study environment at Medical College during a period of rapid changes. It describes the requirements of the environment and return on preparing professionals for regulated professions. These factors determine a dynamic activity optimization of a first level professional higher education institution by providing innovative solutions for the achievement of its mission, vision and goals. The results achieved allow planning viable development, new core programs that mark early clinical experience, the monitoring of individual skills (for all process participants), the elasticity of studies with high average level of graduates reaching the adequacy of the proposed goal, profession's standard and society's good understanding of resource allocation topics.

Special attention was paid to the development of gradual comprehension process where one moves from simple to more complex process understanding by developing critical thinking skills, scientific research and other skills. For every year's study process assessment, there are indicators identified, the analysis of which show the results, the process correspondence with the industry politics, and expected development. The circulation of this process is discussed via student individual and practical work percentage increase at the study program. The cooperation degree among process participants and the tendencies, coefficient and obstructive factors in different aspects were also analyzed.
\end{abstract}

This work has been supported by the European Social Fund within the project "Support for Doctoral Studies at University of Latvia."

Keywords: research; systematic; scientific research; study program; study process; systemic change; development; innovation; knowledge management

\section{INTRODUCTION}

urrently, Medical College intensively works on the assessment of how its offer of programs corresponds to all: modern demands, the profession's standard, and potential future development. Another equally important topic is the implementation of the study program and simultaneous awareness of its achievements, the analysis of the goals achieved and the ability to measure them relatively. In order to notice conducive and obstructive factors, as well as find optimum solution, one has to view the process occurring at the college as a common system and examine indicators that would best describe the efficiency of the functioning of this system. The broader the view on the process flow and the more analytical approach, the more precise action result when reorganizing the process as the component of a system.

It is evident that successful systemic reform will depend on access to and effective use of large amounts of data. This means that the quantity, timeliness, and level of detail of the data needed from decision-support systems will only increase. Proponents of systemic reform point to the importance of a process model and evaluation framework for assessing programs (Clune, 1998). Well considered changes in a particular stage affect the whole system, therefore the result changes not only in the part was changed but also in the general system. 
The paper explores research that analyzes possible indicators such as the democratization of the system, study process and its content, target-oriented result - skills, abilities (competencies) and the organization's dynamic development.

While reconsidering possible changes, the necessary pre-requisites to ensure better training of a graduate the future professional - for its chosen profession were taken into account. Emphasis was removed from problemoriented studies and put on result-oriented studies thus backsliding from the prejudices inherited from the former study system.

In cooperation with social partners, the author proposed hypothetical questions: (1) if it is possible for college graduates to shorten the adaptation period when starting practical career, and (2) if it is possible to more dynamically obtain abilities and skills according to the rapid pace of medicine's development. Proposed questions were based on the observations that graduates need a relatively long period to adapt to working environment in real conditions and their initial contribution to the common process should be better-read. Possible solutions were found in doing earlier individual work in different forms and assimilating in study programs, with well-considered opportunity of dynamic assessment that would allow implementing changes more flexibly.

As a result, the specifics of individual work and scientific research activities and their effect on the pre-set goal at the educational institution were analyzed. In-depth analysis and the search for possible solutions were related to re-orienting the study process to dynamic assessment of programs from interdisciplinary perspective and to its compliance with the goals, student individual work, learning from experience and mutual cooperation, early clinical internship and other aspects. Eventually, one has to find the answer on the possible solutions both for obtaining qualification at the promised level during the study process and for workers in the perfection of their skills and abilities. In order to analyze the process flow in the study process and the effect of processes on the final result, it is necessary to divide it into separate parts - modules - and define measurable results (indicators) for each of them. These results would show the level of student preparedness as well as their degree of influence on the system. The relative grouping does not match with the boundaries of the study year as there is a pre-determined sequence according to both content and complexity level of the program.

The study program was analyzed as a part of the system. This ensures discussing possible results as the indicator of a particular cycle and putting emphasis on individual and scientific research work and its effect on the final result: the formation of skills and abilities (competences).

\section{THE SPECIFICS OF THE STUDY PROCESS AT MEDICAL COLLEGE}

In the study process at Medical College, scientific research possesses the features of practical research. During the first study year in particular and considering the complexity of health care and the uneven nature of society's receptiveness over time and space, research activities possess innovative features. On one hand, society awaits a well prepared professional who already has proven skills in performing complex activities with the aim of stabilizing the situation under complicated (like the medical industry in essence is) conditions in the particular case, but on the other hand there are limited resources to provide for that.

The changes in the study process are related to both (1) dynamic change of program content based on the results of systemic research and analysis on the achievements and long-term needs and (2) familiarizing oneself with the study material where students' individual work, scientific research and multidiscipline clinical practice are of great importance, which eventually ensures the preparation of well-demanded and competitive professionals for the labour market. Innovative approach is expressed as the provision for elastic study process, increased student participation in individual projects and scientific research, which allows observing and forecasting the educational institution's potential study program in perspective.

Scientific research approximates a student's learning process to practical understanding of the chosen profession and establishment of skills, which in turn ensures timely professionalization of the prospective medical person. These activities require additional resources, which is worth organizing public debates and discussions. 
Learning proves is characterized by high variability with respect to the progress of medical industry and the ability of studies' participants to explore it, comprehend its external and internal environment, technologies, as well as the systemic nature of processes. In order to reach the learning process target, systemic cooperation process is being established. It balances viable development of study programs providing individual and flexible approach as possible and stressing the possibility to apply theoretical knowledge into practice. As a result, high average level of graduate competencies is reached. To assess the advancement of this process in the study program, measurable indicators were identified. These indicators show the established system's dynamic development and accordance with the goal.

The criteria to examine the skills obtained include the assessment of stable skills to:

- $\quad$ interdisciplinary look at the problem,

- notice the harmonious and dissonant in the data stream,

- make conclusions,

- develop action plan,

- critically assess the dynamics of a process,

- $\quad$ work in a team of professionals,

- $\quad$ tolerate specialist references and skill assessments,

- other.

The level of student knowledge is determined at every stage of studies and thus the study progress is determined by assessing also the quality of available programs and changes needed in the future.

Process-oriented programs provide the opportunity to establish result-oriented studies, which is possible by increasing the formation of personal experience by practising in real working environment. Interdisciplinary teaching, disperse practice platforms in different clinics, and interdisciplinary dialogue by approaching the same issue from the perspective of different specialists - all promote a student's critical approach to case studies by developing innovative thinking that in turn promotes participation in scientific research.

Study process postulates high requirements for a student: organization, pro-activeness, motivation, creativity etc. The mentioned requirements are the pledge for a student to successfully deal with the intensity of studies offered by the college. In order to successfully finish the program offered by the educational institution and motivate a student to change its habitual study style to self-initiative in reading study materials in a shorter period of time and with less mental effort, it becomes important to evaluate student adaptation to the study environment. Pedagogy and psychology understands the term adaptation as a personality's optimum compliance with the external environment as a result of human activity that allows the person to satisfy its education needs and achieve goals related to education.

When starting studies at Medical College, students have to study and work a lot in order to formulate their philosophy of life, and to improve and strengthen their professionalism for working as a doctor. Study process at the Medical College is not similar to high school studies since students have to take courses in both soft and natural sciences. Many study courses and the organization of studies are still unfamiliar to students and they are not used to work independently with different information sources, organize the collected information and filter out the necessary information from the enormous amount of information available. It requires a lot of effort and energy. Some could do that in their previous educational institution (school), but others have to do that at the college.

Adaptation depends on individual factors such as the ability to make decisions independently, the understanding of values, ability to plan and to realize the planned, the degree of critical thinking and other factors that directly affect a student's results. A person's resources and social support from close people and new friends ensure successful integration in to the college's environment. A young person's psychological wellbeing and the effectiveness of self-realization in this age period (18- 20 years) are related also to strengthening one's personal and professional identity, the achievement of desired goals, the formation of future career opportunities, and the maintenance of mental health. The discovery of one's individuality in a new group of people is an important 
precondition for successful studies. The importance of adaptation at this stage is obvious; therefore it is necessary to consistently promote it in order to achieve the desired results.

Human life is continuous adaptation to circumstances, learning new roles, involvement in new relationships. Socializing is an infinite process. A young person's readiness to make the choice, his belief in his abilities after obtaining a high school degree and having learnt the norms, values and verities related to professional activity has special importance. Nobody will ask him definitions, birth dates of famous people. What will be asked is the ability to orientate oneself in situations.

Adaptation process occurs in one way or the other, independent of the way how the study year starts at the college. Professors assist students in learning how to use study tools and manage the study process. It is important to propose motivated goals, choose appropriate means, use both intellectual and practical skills, control the study process, predict and adjust further study process.

Qualitative interaction among pedagogical process components will promote effective adaptation in changing environment and will not endanger the physical and psychological wellbeing of a person. The case of poor quality interaction, in turn, will cause the adaptation to be inefficient and this can jeopardize the human body by harming physical and psychological wellbeing and thus creating tension.

One of important aspects of adaptation is the orientation of values. The effectiveness of the process of choosing a profession is ensured by a person's active acquisition of professional knowledge, skills and abilities, student's motivation and value orientation. The professional adaptation of a student depends on how important the chosen profession, work, and success are for the student; what requirements the student has for himself, his professional activity, and his future employee; how the student reacts to failures in the study process. During the adaptation process, the reorganization of needs and motivation takes place. Therefore professor task is to ensure that students have developed permanent professional values.

It was possible to observe differences in the development of permanent abilities during the study process between students that volunteered for extra-curricular scientific research projects and students that fulfilled the program's requirements. Students that participated in the projects developed more stable abilities to work independently, more distinct determination and shorter adaptation process in the study environment.

The study programs available at the college are related to preparing specialists in regulated professions that are subject to profession standard. In the course of time the profession standard is reviewed, achievements are analyzed, and future-oriented development is drafted. In this process, one has to particularly stress the importance of process environment, participant skills, and the model of institution's administration.

\section{SCIENTIFIC RESEARCH AND KNOWLEDGE MANAGEMENT}

Knowledge management is most commonly expressed in scientific research and as a planned, thought-out process. Scientific research is systemic, controlled, empirical and critical exploration of natural phenomenon led by theory and hypotheses on possible relationships among phenomena (Geske, A.; Grinfelds, A. 2006).

The definition of scientific research stresses the main principle that every student researching a project at the college should comply with. This principle is the consistency of work. The advancement of work should occur advisedly planned and continuous in a specific time period. The research period should be finite.

Research and knowledge management are the features of a common system. They show the consistency of the process, the intellectual potential of an institution and its ability to see development in the future. The application of acquired knowledge provides the development and maintenance of skills and abilities for all study process participants. Always a topical question is the integration of circulating knowledge horizontally and vertically since on top of maintaining the intellectual potential for the developers and organizers of study programs it is also necessary for the implementers. Knowledge circulation is as a closed system. If the acquisition of knowledge and its effective application to the environment is ensured, then we get knowledge development with high value added. 
In the learning process, the administration of processes and the result achieved are essential. Key prerequisite for the administration of these processes is targeted planning based on the analysis of achievements and forecasts on the options in the long run. Consistent flow of this process is ensured by data bases created for the needs of both studies and scientific research.

It is necessary to assess the study environment as a relatively closed system that is well controllable, analyzable, predictable and viable in the long run. While implementing this model, the competence of the participants and specialists involved has dynamic nature and thus they become the experts of their field, but their knowledge is transformed into the company's knowledge. Therefore the data base at the educational institution dynamically improves and it more conveniently allows users to be aware of the achievements, to propose new research questions, objectives, tasks and to find innovative solutions, since healthcare field is complex and simple solutions are not possible.

Innovation is doing something better or new. This is knowledge development, shown above, where new knowledge or technology can be created or discovered or new applications of technology can be found (Diem Ho, 2007). Rapid development of medicine science changes the comprehension of disease origin, progress, possible diagnostics and treatment. It all promotes dynamic transformation of study programs and require innovative approach from the study process participants in studying them. In addition to that, medical technologies and the environment are rapidly changing which imposes additional necessity to have a common and continuously improvable data and information base that works in a closed system.

Such a closed system is referred to as the model of knowledge management. Knowledge management is in fact the process of managing the knowledge cycle. The knowledge cycle consists of three pillars: the knowledge/technology acquisition, the knowledge/technology assimilation, and knowledge development (Diem Ho, 2007). According to the classic view, knowledge management is understood as dynamic circulation of human knowledge inside an organization and the application of information technologies to ensure this process. The process task is to deliver as soon as possible the largest possible amount of the knowledge employees continuously improve at the institution's disposal. Hence, due to different change processes, the established practices will not be lost as the executives change and the number of situations when reforms are completed but the initiative of the particular employee remains unnoticed because of the enterprise's incomplete knowledge management system will be minimized. Knowledge management promotes reforms that aim at using resources as rationally as possible to achieve particular goals (production volume, increase in profit etc.). This approach in knowledge management has changed and it all is regarded as the optimum use of resources and stock as the system continuously develops. There is always this open question: which knowledge is a resource to be managed and which are not. The set of knowledge that includes experience, human intellect, social and professional knowledge all together form a specialist's internal knowledge. By implementing knowledge management methods in an enterprise, knowledge data base starts developing. It includes what is required by laws and regulations (accounting, documentation and other) and the employee created data base that stores the new knowledge obtained by employees as a result of their activity. The definitions of knowledge management are as many as there are researchers of this process. All definitions are united by terms the formation of human knowledge and experience, search of topical information, selection, formation and distribution within the boundaries of the system. One can say that it is continuous monitoring of an employee that is documented in electronic form under the condition that everything is done in the virtual environment. Knowledge management is oriented towards an organisation's management, strategy, the provision of continuous improvement and circulation of knowledge and other processes. The idea that knowledge management as a method can develop education environment and promote gaining knowledge comes from the American and European entrepreneurship school.

The creation of a knowledge management model can be divided into two stages. The first stage includes the management of existing knowledge (resource identification, more efficient use of resources, selection of and updating knowledge basis, maintenance and development of knowledge infrastructure). At the second stage, new data and knowledge base is developed via reorganization and optimization of the study process, scientific research and other processes. 
In order to discuss knowledge management at study or research process, one has to understand the differences among data, information and knowledge. Neil Fleming claims that:

- A collection of data is not information.

- A collection of information is not knowledge.

- A collection of knowledge is not wisdom.

- A collection of wisdom is not truth.

Despite its volume, data, unless collected, analyzed and systemized, does not become information. Separate data, for instance, the result for sex and age obtained in different tests. If this data is not combined into the system and it does not answer the question on the dynamics of the particular process and it does not become the information of the IT system. Information has several features such as meaning, goal, and volume to compare it to similar in substance information. Information in circulation to some extent relates to experience and intuition and it serves as the base for drawing conclusions and creating knowledge.

There are quite many definitions of knowledge management in the available information space. Yet, each of them is defined according to a particular situation where it is applied, which per se indicates at the complexity of the process and the desire to have one's own understanding of the concept.

By Kidwell Knowledge management is the process of transforming information and intellectual assets into enduring value. It connects people with the knowledge that they need to take action, when they need it. (Kidwell, Jilinda J., Vander, Linde Karen M.,Johanson, Sandra L (2000).)

Knowledge management model is directed at the promotion of intellect, yet, one has to disclose the core stages of the process when discussing it. One can describe this process as the transformation of simple facts and number into specific background that becomes structured information that is stored in data bases (written or electronic documents). But the most crucial emphasis in this process is on the intellectual contribution of each data base user, which ensures more creative development of the data base.

Common feature in the description of this process is the fact that information becomes knowledge only when it is combined with experience and judgement (it includes human understanding and wisdom). This value gained functions in continuous flow among people affecting the decision making process.

Knowledge management allows the system users to find not only knowledge expressed in words (defined), but also opinion on things, events and forecasts, i.e., knowledge not expressed in words. Knowledge expressed in words is limited to the description of strategy and methodology etc. But knowledge that is not expressed in words is the most important acquisition of this process since it talks about skills, competences, experience, and the value system.

Well adjusted management system gives the opportunity for the process participants to receive necessary amount of knowledge within the required timeframe. As a result, one can observe increased demand for more convenient IT solution that in turn would ensure the opportunity to solve situation from interdisciplinary perspective and develop the results of one's own work with explicit innovation features.

Comprehending student variety by skills and study forms, knowledge management process is largely ensured by IT data base. It can be used for both creating knowledge and organizing its flow especially during the period of reforms in the educational system. A person participating in either local (administering an institution, libraries, distance-learning and other) or broad (educational system) data bases has to be prepared and it has to comprehend the system where they work both in substance and according to opportunities to achieve a particular goal.

The development of data bases has a great effect on the provision and promotion of scientific research. Research process promotes not only the use but also the development of the data base. As a result of scientific research, new data is obtained that promotes further research process after feeding them into the data base. The 
understanding of and learning research methodologies promote the ability to work independently with information, select, organize and analyze it.

The study environment provides student individual work including scientific research, application of theory to practice and cooperation among the participants of the study environment. The participants of the study environment are not only students and professors, but also the integration degree of the institution's administration processes from the perspective of competencies. Scientific research plays a crucial role in the maintenance of this process: it is the indicator of the whole system.

Research is needed to use existing knowledge and to create new knowledge. It is the means for maintaining intellectual leadership. Knowledge management is the solution for sustaining a competitive edge in a knowledge economy (Diem Ho, 2007). The provision of scientific research activities at all levels serves as the guarantee for stable functioning of the study environment. Study environment is stressed as a virtue via the compliance of available programs to the objective, student individuality, industry, and society's demand.

To achieve the proposed objectives, it is necessary to have a dynamically developing storage of data and information that is ensured by the latest generation information technologies (IT). By developing the study environment of medical college as a controllable system, one can observe the change in attitude towards the achieved as well as the formation of more active viewpoint that is directed to the industry in the long run from all its participants.

Larger amounts of knowledge are united by principal patterns. By understanding them, we develop our own competences that are the basis of each specialist's wisdom. Therefore one can claim that consistent work within particular process flow continuously improves a person.

It is perhaps easiest to understand knowledge in terms of what it is not. It is not data and it is not information. Data are objective facts, presented without any judgment or context. Data becomes information when it is categorized, analyzed, summarized, and placed in context. Information therefore is data endowed with relevance and purpose. Information develops into knowledge when it is used to make comparisons, assess consequences, establish connections, and engage in a dialogue. Knowledge can, therefore, be seen as information that comes laden with experience, judgment, intuition, and values. (Thorn, C.A. (2001, November 19) by Empson, 1999). The data obtained becomes information under condition that data is processed, analyzed, organized and the result becomes easy-to-use in the system that aims at assimilating the obtained and forming new knowledge.

The result obtained can be considered as the system's indicator and, if it does not meet expectations, then it is necessary to make adjustments after analyzing the ongoing process as a united model. Adjustments should be complex stressing the long run needs.

One of the system's viability indicators is the ability of its participants to achieve pre-set objectives, analyze the process, and participate in forecasting the future. As a result, one can claim that the level of participant activity and the opportunity to affect the ongoing reflect the systemic process as a dynamically developing approach. Systemic change suggests a change of the system rather than within the system. Both inner (personal-psychological) learning and outer (social-psychological) learning are required for the systemic change process to occur. (Menchaca, Marylu, 2004).

It means that there has to be high enough motivation to make these efforts result in changes in the process participant and society. Democratic administration of the institution strengthens these changes. Progress in technology and formation of student-centred study environment require awareness of each process's result as the system's functionality indicator that positively or negatively describes the achievements. By analyzing the achieved and considering the dynamic changes in the study process at the college, there were several research projects prepared and executed. The analysis included the study process, internal and external environment. In addition, a healthcare project was prepared and executed. Work on the project was proposed as a voluntary activity in the study process. It allowed assessing the change in the student's attitude towards extra curricular activities, the formation of skills and abilities in comparison to peers, the familiarization with research skills and their application to core programs comparing to the average statistics at the college. 
Meanwhile, measurable and analyzable indicators for the study program were identified. They were sorted from the simplest to the most complex: from the recognition of problems and phenomena till analysis, selection, data organization so that it becomes logically created information for making conclusions, planning further activity, and developing the monitoring of further processes. Target-oriented study process to achieve particular abilities and skills was developed.

Observations:

- $\quad$ Participation among process participants increased not only among students but also with professors along with the increase in the percentage of individual work at the study program. Thus students and professors were working at the cooperation partner level which means that knowledge assimilation from practice also increased.

- Vertical and horizontal cooperation among process participants increased, which thus marked the most urgent issues that need assessment and adjustment in order to improve the viable progress of study programs.

- The identification and assessment of indicators during the study program processes provides faster opportunity to notice negative tendencies and allows making adjustments and thus considerably saves resources while improving the effectiveness of the system.

- Over time, student interest in participation in extra curricular projects has increased. The statistical proportion (expressed as a percentage) of voluntary students over the total number of students in the Doctor Assistant program: $10 \%$ in year 2007, 13,5\% in year 2008, 25\% in year 2009, and 31\% in year 2010 .

- In the grading scale of 10 points, voluntary students had 2.2 points higher GPA compared to an average student.

- $\quad$ These students were particularly active in the assessment and analysis of the type and content of available study programs. The results served as indicators for the administration to analyse the available programs and make adjustments to the study process.

- $\quad$ Social partners offered job positions to $100 \%$ of voluntary students as opposed to $78 \%$ of other students.

- There is a positive correlation between (1) increased scientific research and the amount of student individual work during the study program and (2) graduate professionalization and sooner adaptation to the working environment.

- $\quad$ Obstructive factors:

$\circ \quad$ Limited resources (information technologies, software and other);

$\circ \quad$ Insufficient understanding of the importance of feedback from the viewpoint of united system and other.

This article examines the innovative nature of processes in the study process at the medical college, its expressions depending on environmental factors, innovation opportunities and their impact in the process of creating competencies.

Research process from the particular perspective has just begun. Only after a longer period of time it will be possible to evaluate the process more precisely and to develop it more flexible and sensitive to changes in environment.

\section{CONCLUSIONS}

The main conclusions from research results:

1. Study environment should be considered as a system that has its own activity nature, processes and any result is the indicator of the system showing the consistency of the system's operations.

2. The offering of study programs should be flexible considering student needs and labour market analysis.

3. Criteria for study program results should be clearly defined and measurable. They should be regularly analysed and adjusted in accordance with the environment's requirements and profession's standard.

4. Learning process should be result-oriented, and individual work and scientific research promote resultorientation. 
5. Scientific research promotes sooner student adaptation to the study environment, independence, formation of skills and abilities, argumentation of one's own opinion.

6. The participants of the study environment should be cooperation partners and it promotes the preparation and execution of a viable study program in the long-term.

7. Cooperation with social partners helps to develop communication skills and understanding of the external environment.

\section{REFERENCES}

1. Clune, W. H. (1998). Toward a theory of systemic reform: The case of nine NSF Statewide Systemic Initiatives. Research Monograph 16. Madison: University of Wisconsin, National Institute for Science Education

2. Diem Ho Research, Innovation and Knowledge Management: the ICT Factor Submitted to UNESCO, July 20, 2007 http://portal.unesco.org/education/en/files/55811/12015104365Ho final_versionEN.pdf/Ho_final\%2Bversi onEN.pdf

3. Fleming, Neil. Coping with a Revolution: Will the Internet Change Learning?, Lincoln University, Canterbury, New Zealand 2000

4. Geske, A; Grīnfelds, A (2006). Izglītības pētniecība (Researching Education). LU Akadēmiskais apgāds. Riga, 2006

5. Harden, R.M. (2002) Learning outcomes and instructional objectives: is there a difference? Medical Teacher, 24, pp. 151-155. http://www.informaworld.com/smpp/content $\sim$ content=a713687076\&db=all

6. Kidwell, Jilinda J., Vander, Linde Karen M.,Johanson, Sandra L (2000). Applying Corporate Knowledge Management Practices in Higher Education? Available http://www.educause.edu/ir/library/pdf/EQM0044.pdf http://net.educause.edu/ir/library/pdf/EQM0044.pdf

7. Menchaca, Marylu, Bischoff Michael, Dara-Arbams Benay A Model for Systemic Change Management in Education Journal on Systemics, Cybernetics and Informatics 2004. VOLUME 2 - NUMBER http://www.iiisci.org/journal/CV\$/sci/pdfs/P706915.pdf

8. Thorn, C.A. (2001, November 19). Knowledge Management for Educational Information Systems: What Is the State of the Field?, Education Policy Analysis Archives, 9(47). Retrieved [date] from http://epaa.asu.edu/epaa/v9n47/.

9. Brennons Džons - project manager. Kvalitātes rokasgrāmata: Procedūras un prakse (Quality manual: Procedures and Practice). Phare Multi country program in the highest education. European Education Fund, 1998.11. http://www.aic.lv/ENIC/lat/enic/dipl_atz_dok/saturs.htm 
International Journal of Management \& Information Systems - Third Quarter $2011 \quad$ Volume 15, Number 3

NOTES 